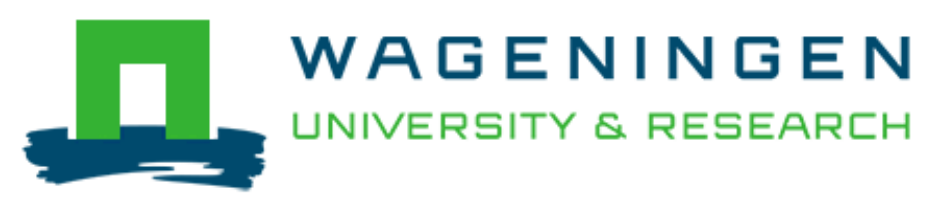

Importance of harmonised sample preparation for moisture and protein content determinations in official food control laboratories: A poultry meat

\author{
case study
}

Weesepoel, Y., Silletti, E., Alewijn, M., \& Bernreuther, A.

This is a "Post-Print" accepted manuscript, which has been Published in "Food Chemistry"

This version is distributed under a non-commercial no derivatives Creative Commons (c) (1) $\Theta(\Theta$ reproduction in any medium, provided the original work is properly cited and not used for commercial purposes. Further, the restriction applies that if you remix, transform, or build upon the material, you may not distribute the modified material.

Please cite this publication as follows:

Weesepoel, Y., Silletti, E., Alewijn, M., \& Bernreuther, A. (2019). Importance of harmonised sample preparation for moisture and protein content determinations in official food control laboratories: A poultry meat case study. Food Chemistry, 301, [125291]. https://doi.org/10.1016/j.foodchem.2019.125291

You can download the published version at:

https://doi.org/10.1016/j.foodchem.2019.125291 


\section{Journal Pre-Proof}

Importance of harmonised sample preparation for moisture and protein content determinations in official food control laboratories: A poultry meat case study

Yannick Weesepoel, Erika Silletti, Martin Alewijn, Alexander Bernreuther

PII:

S0308-8146(19)31401-3

DOI: https://doi.org/10.1016/j.foodchem.2019.125291

Reference:

FOCH 125291

To appear in:

Food Chemistry

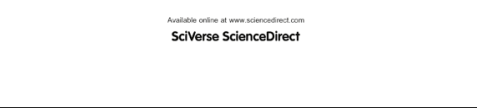

Received Date: $\quad 31$ March 2019

Revised Date: $\quad 25$ July 2019

Accepted Date: $\quad 28$ July 2019

Please cite this article as: Weesepoel, Y., Silletti, E., Alewijn, M., Bernreuther, A., Importance of harmonised sample preparation for moisture and protein content determinations in official food control laboratories: A poultry meat case study, Food Chemistry (2019), doi: https://doi.org/10.1016/j.foodchem.2019.125291

This is a PDF file of an article that has undergone enhancements after acceptance, such as the addition of a cover page and metadata, and formatting for readability, but it is not yet the definitive version of record. This version will undergo additional copyediting, typesetting and review before it is published in its final form, but we are providing this version to give early visibility of the article. Please note that, during the production process, errors may be discovered which could affect the content, and all legal disclaimers that apply to the journal pertain.

(C) 2019 Published by Elsevier Ltd. 


\title{
Importance of harmonised sample preparation for moisture and protein content determinations in official food control laboratories: A poultry meat case study
}

\section{Yannick Weesepoel ${ }^{\mathrm{a},{ }^{*}}$ Erika Sillettia ${ }^{\mathrm{a}}$, Martin Alewijn ${ }^{\mathrm{a}}$ and Alexander Bernreuther ${ }^{\mathrm{b}}$}

${ }^{a}$ Wageningen Food Safety Research, part of Wageningen University and Research, P.O. Box 230, 6700 AE Wageningen, The Netherlands

b European Commission, Joint Research Centre - Geel, Retieseweg 111, 2440 Geel, Belgium

* Corresponding author Yannick Weesepoel. Phone: +31317480356; Email address:

\section{Yannick.weesepoel@wur.nl}

Running title: Sample preparation effect on poultry meat moisture and protein content

\begin{abstract}
Commission Regulation (EC) 543/2008 limits moisture and protein contents in poultry meat. However, this regulation leaves room for interpretation regarding sample homogenisation, potentially affecting comparability of laboratory results. Therefore, a proficiency test and sample homogenisation study were organised amongst 19 European National Reference Laboratories (NRL). In the proficiency test, three different pre-homogenised chicken samples (fillets, drumsticks and carcasses) were analysed. Only one NRL produced unsatisfactory results. In the homogenisation study, NRLs were supplied with uniform fillet, drumstick and carcass materials. Homogenisation was performed according to the NRLs in-house methods. Five NRLs did not return satisfactory results. As these NRLs produced satisfactory results in the proficiency test, their increase in z-scores was related to their homogenisation practices. Overall, scattering of individual results was higher for drumsticks compared to fillets and carcasses. Homogenisation practices for poultry meat introduced significant differences in moisture and protein results and standardisation is therefore advisable.
\end{abstract}




\section{Keywords}

moisture content; protein content; sample homogenisation; proficiency test; poultry meat 


\section{Introduction}

The moisture and protein content of poultry meat is an important indicator of its quality and authenticity. Therefore, European Union regulations concerning these macro-components have been in use since 1975, with the latest Council Regulation (EC) No 1234/2007 laying down marketing regulations for all agricultural products. Marketing standards for poultry meat are further elaborated in Commission Regulation (EC) No 543/2008, which describes the legal limits for maximum water content (carcasses, Annex VII) and water/protein ratios (poultry cuts, Annex VIII). To accurately determine the described maximum limits for carcasses and poultry cuts, a robust determination of moisture and protein content is required. The procedure for calculating maximum moisture content and moisture/protein ratio is described in the corresponding legislative text and will not be elaborated further upon in this study. In the European Union, the National Reference Laboratories (NRLs) are, amongst other tasks, responsible for "coordinating activities of the national laboratories responsible for water content analyses in poultry meat" and "assisting the competent authority in the Member State in organising the system for monitoring water content in poultrymeat (sic)" (for more details see Annex XII of Commission Regulation (EC) No 543/2008).

The recommended method for determination of moisture in poultry meat is ISO 1442 (International Organization for Standardization, 1997). Although the Commission Regulation (EC) No 543/2008 utilises the term 'water', the ISO 1442 method for determination of this parameter speaks of 'moisture'. Throughout this work the term 'moisture' will be used as it corresponded to the ISO method rather than the legislative text. The ISO 1442 methods prescribes oven drying to physically separate the moisture from the sample. The moisture content is directly determined by gravimetry. Although more accurate direct methods for determining moisture are available (as for example Karl Fischer titration), oven drying methods can be carried out in virtually all laboratories giving reproducible results when executed properly (Isengard, 1995). The recommended method for nitrogen content determination in meat and meat products is ISO 937, using the procedure of Kjeldahl (International Organization for Standardization, 1978). Alternatively, the Dumas method for the 
determination nitrogen in meat and meat products can be used although bias correction should be applied (Thompson, Owen, Wilkinson, Wood \& Damant, 2002; Thompson, Owen, Wilkinson, Wood \& Damant 2004). Quality control of the Kjeldahl method analytical results is of utmost importance in order to obtain accurate results and were extensively described elsewhere (Sáez-Plaza, Navas, Wybraniec, Michałowsi \& García Asuero, 2013). By means of proficiency testing on prehomogenised samples, the laboratory performance (analytical error) can be monitored (Thompson, Ellison \& Wood, 2006).

Sampling and sample homogenisation is required prior to moisture and protein content analysis, and is considered a major source of error (Sáez-Plaza et al., 2013). The sampling size and homogenisation procedure for poultry carcases and cuts is described in Annex VII and VIII of Commission Regulation (EC) No 543/2008. However, the Regulation merely gives operational guidelines on the sample homogenisation and does not strictly and unequivocally describe how this step should be performed by the laboratories. This can lead inevitably to varied interpretations of the regulation itself and diverse experimental practices, as for example in the storage conditions, processing temperatures and particle sizes of the sample after homogenisation.

This sample processing step plays a crucial role in the above-mentioned determinations and can have large consequences in assessing whether samples are compliant with the current legislation. A survey conducted in 2014 amongst 20 NRLs on monitoring moisture content in poultry meat confirmed that there are multiple interpretations among the European Member States regarding the sample homogenisation method described in Commission Regulation (EC) No 543/2008 (results not published). The results showed that poultry samples were, for example, conditioned and/or homogenised at different temperatures, using different equipment, which can have an effect on the sample homogeneity and therefore moisture and proteins content results between different laboratories.

In addition to the uncertainty around the sample homogenisation procedure and the actual influences on the final results, it appears that, for example, the use of new technologies during poultry 
cuts productions (i.e. new introduced slaughter house chilling methods) as well as the nowadays growing conditions of poultry might have an effect on moisture contents as two recent studies conducted in 2012 and 2016 showed. In these studies, the physiological moisture content of European poultry and the influence of the slaughterhouse chilling methods respectively, have shown that the 1993 limits might require a re-evaluation (Elahi \& Topping, 2012; Elahi \& Hopkins, 2016). In fact, according to the 2012 study poultry meat contained slightly more moisture and slightly less protein when compared to the results from the 1993 study (European Commission, 1993).

In light of the current knowledge and the merely standardised sample homogenisation protocol in the legislative texts, the effect of sample homogenisation prior to moisture and protein content measurements should be investigated amongst different laboratories for poultry meat. Therefore, the aim of this study was twofold. Firstly, to assess whether comparable results are obtained from laboratories across Europe upon analysis of proficiency test samples. Secondly, to gain insights on the effect of sample homogenisation methods practised amongst 19 NRLs (18 NRLs reported results). To this purpose, we set up a proficiency test and a homogenisation study on the moisture and protein content of poultry meat among European NRLs.

\section{Materials and Methods}

\subsection{Reagents and materials}

All reagents used in moisture and protein content analysis were of analytical grade and according to ISO 1442 and ISO 937 (International Organization for Standardization, 1997; International Organization for Standardization, 1978). NRLs did not report deviations from reagents used in both ISO methods.

Two poultry meat cuts (i.e. chicken breast fillet without skin and chicken drumstick) and poultry (chicken) carcasses were used in both proficiency test and homogenisation study. As some NRLs do not routinely analyse one or two of the materials offered by the study organisers, it was advised to only participate in those parts where experience exists. Therefore, each participant was 
free to choose which material to analyse (i.e. one, two or all three types). It was a prerequisite that sample types chosen for the homogenisation study were also analysed by the NRL in the proficiency test, to verify their analytical capability for the particular sample type.

Chicken fillets (without skin), chicken drumsticks (with skin) and chicken carcasses (with skin, without giblets) were purchased from Plukon B.V. (Dedemsvaart, The Netherlands). For the proficiency test, sufficient amounts of fillet, drumstick and carcass materials were frozen prior to homogenisation (see Section 2.2). In case of the homogenisation study, in order to ensure the uniformity of the material within the sample type, individual samples were collected from the same flock, age and breed of birds. For this purpose, 600 pieces of fresh chicken cuts and 90 pieces of fresh chicken carcasses were shipped to the organising laboratory by cooled transport immediately after slaughter.

\subsection{Sample preparation}

For the proficiency test, chicken fillet samples were conditioned by liquid nitrogen and were homogenised by an industrial blockbuster BFBB 200.250 (Boldt Industries, Hudson, OH, USA) followed by a Stephan UMC 5 Electronic mill (Stephan Machinery GmbH, Hameln, Germany). Chicken drumsticks and carcasses underwent the same procedure as the chicken fillets, but were subjected to a third homogenisation step using a small bench-top mill with $5 \mathrm{~cm}$ quadrupole blades (Retsch GmbH, Haan, Germany). During the homogenisation process, the sample temperature was below $-20^{\circ} \mathrm{C}$ by addition of liquid nitrogen. Immediately after completing homogenisation, plastic containers $(100 \mathrm{~mL})$ were filled randomly with approximately $50 \mathrm{~g}$ of homogenised material and kept at $-20{ }^{\circ} \mathrm{C}$ prior to shipping. Samples (3 sample containers of each sample material) were shipped to participating NRLs on dry ice and were delivered within $72 \mathrm{~h}$. Upon receiving, homogenised samples were stored at $-20^{\circ} \mathrm{C}\left( \pm 5^{\circ} \mathrm{C}\right)$ until further use.

For the sample homogenisation study, chicken fillets and drumsticks did not receive any form of pre-treatment. Samples were double-bagged (5 cuts per sample, 6 samples of each cut sample 
material) prior to shipment $\left(4\right.$ to $7^{\circ} \mathrm{C}$ ) to the participating NRLs. Chicken carcasses were inspected for any remaining giblets and cut transversely by an electrical handsaw (Black \& Decker KS880EC, Towson, MA, USA). Three pieces of halved carcasses (3 samples were sent to the NRLs requesting carcass samples) were double-bagged prior to cooled shipment (4 to $7{ }^{\circ} \mathrm{C}$ ). Although this sample amount deviates from the prescribed sampling in Commission Regulation (EC) 543/2008 (7 whole carcasses per sample), for logistical and practical reasons 3 half carcasses were shipped. Upon receiving samples, NRLs were instructed to evaluate the correct condition of the fresh cuts. In order to prepare the samples for moisture and protein content measurements, participants (indicated throughout this paper with a numerical code) were asked to homogenise the received material using their in-house homogenisation procedure, in accordance to specifications in Annex VII and Annex VIII of Commission Regulation (EC) No 543/2008, respectively. Participants were also asked to record parameters such as temperature of the samples after homogenisation, duration of the homogenisation and equipment type. Homogenised samples were stored at $-20{ }^{\circ} \mathrm{C}\left( \pm 5^{\circ} \mathrm{C}\right)$ until further use.

\subsection{Moisture and protein content determination}

Sample material was thawed and kept at $4{ }^{\circ} \mathrm{C}\left( \pm 2{ }^{\circ} \mathrm{C}\right)$ prior to measurements. Before analysis, to ensure proper sampling, the homogenised sample was mixed for at least 1 minute. Each sample was analysed in duplicate for moisture and protein content.

Determination of moisture content was performed according ISO 1442 (International Organization for Standardization, 1997). To measure the protein content, nitrogen content was determined first in accordance with ISO 937 (International Organization for Standardization, 1978). Then the nitrogen content was converted to crude protein content by multiplying it by the factor 6.25 as specified in Commission Regulation (EC) No 543/2008. The results of the measurements were accepted if the repeatability criteria described in ISO 1442 (for moisture) and ISO 937 (for nitrogen) 
were met. Moisture content measurements were accepted, if the absolute differences between two independent single test results were not greater than the repeatability given by equation 1 :

$$
r=0.593 \%+0.0017 w \quad \text { equation } 1
$$

where $r$ is the repeatability and $w$ is the moisture content of both results, expressed as a percentage by mass. Protein content determination was accepted, if the repeatability was not greater than $0.10 \mathrm{~g}$ nitrogen per $100 \mathrm{~g}$ sample.

\subsection{Sample homogeneity, sample stability and statistical evaluation}

To test the homogeneity and the stability of the homogenised samples, ten samples of each type of poultry material (i.e. fillets, drumsticks and carcasses) were randomly selected. They were subjected to moisture and protein content determinations by the organising laboratory, which evaluated the homogeneity of the whole study material according to ISO 13528 (International Organization for Standardization, 2015). The target standard deviation $\left(\sigma_{\text {Target }} \%\right)$ was estimated based on a previous study (Elahi and Hopkins, 2016) and it was fixed for this study for both, moisture and protein contents at $1.0 \%$ for fillets, $1.5 \%$ for drumsticks and $2.0 \%$ for carcasses. The materials were considered being homogeneous when the between-samples standard deviation was below $0.3 * \sigma_{\text {Target }}$.

The stability of fillets, drumsticks and carcasses was evaluated by assessing them after 28 days of storage at -20 and $-80{ }^{\circ} \mathrm{C}$. Three samples per temperature and time were measured in duplicate. Both, moisture and protein contents were evaluated according to the requirements of ISO 13528. Samples were found to be stable for the duration of the study.

Participants were provided with three samples of each chosen type of material and were required to report two individual results for moisture and protein for each sample. Though this was a deviation from standard proficiency test practices (where only one sample is provided per laboratory), the goal of this exercise was also to assure that the NRL practises were correct. Data were accepted only if the described repeatability acceptance criteria (Section 2.3) were met. Finally, the results were scrutinised for plausibility according to the additional written comments provided by the NRLs. 
The statistical evaluation of the proficiency test results was performed according to ISO 13528 using ProLab software (QuoData, Dresden, Germany). A consensus value was calculated using all accepted results of the participants. Robust z-scores for moisture and protein contents were calculated according to equation 2 :

$$
Z=\frac{x_{l a b}-X_{\text {ref }}}{\sigma_{p t}} \quad \text { equation } 2
$$

where $x_{l a b}$ is averaged result reported by the laboratory, $X_{\text {ref }}$ is the consensus value from the results of all participants and $\sigma_{p t}$ is the robust standard deviation from algorithm A (ISO 13528). The z-scores were interpreted as following:

$$
\begin{array}{ll}
|z| \leq 2 & \text { satisfactory results } \\
2<|z|<3 & \text { questionable results } \\
|z| \geq 3 & \text { unsatisfactory results }
\end{array}
$$

The statistical evaluation of the results of the homogenisation study was performed according to ISO 13528 (International Organization for Standardization, 2015) using ProLab software (QuoData, Dresden, Germany). z-scores were calculated to indicate laboratories, which may have a bias due to the homogenisation method used.

\section{Results and discussion}

The total number of 19 participants were willing to receive samples (19 NRLs), whilst 18 NRLs reported results. As NRLs were free to choose which type of sample materials to analyse, the following number of results were received by the organisers of the study for the proficiency test (PT) and homogenisation study (HS):

- Chicken breast fillet without skin; PT 18 NRLs, HS 18 NRLs

- Chicken drumstick; PT 15 NRLs, HS 14 NRLs

- Chicken carcass; PT 17 NRLs, HS 11 NRLs.

\subsection{Proficiency test}


The proficiency test sample material was found to be adequately homogeneous according to the requirements of ISO 13528, with the exception of the protein results of the carcass material (Table 1). Although the between-sample deviation was relatively high for the protein values, for moisture the material was found to be adequately homogeneous. In addition, all materials proved to be adequately stable at $-20{ }^{\circ} \mathrm{C}$ and $-80{ }^{\circ} \mathrm{C}$ between dispatch $\left(\mathrm{t}_{0}=0\right.$ days $)$ and report date $\left(\mathrm{t}_{1}=28\right.$ days $)$. The results of the proficiency test are reported in Table 2, Figure 1 and Figure 2. The twodimensional representation of the homogenisation study was illustrated in Figure 1A, 1B and 1C with Youden plots. Laboratories inside the green rectangle had "satisfactory results" for both, moisture and protein contents respectively. Laboratories marked with orange diamonds had "questionable results" and laboratories marked with red diamonds had "unsatisfactory results" (for both moisture and protein content).

An overview of the average values reported by each analysing laboratory for moisture and proteins content as well as the calculated z-scores for the used chicken materials (i.e. fillets, drumsticks and carcasses) is reported in Table 2. All labs produced satisfactory results with the exception of Lab 7 and Lab 18 for the moisture content (Table 2 and Figure 1A, 1B and 1C). The results reported from Lab 7 were evaluated as questionable for moisture content in fillets and drumsticks (i.e. $z$-score is 2.51 and 2.22, respectively) but not for carcasses. The data received from Lab 18 for the moisture content were judged unsatisfactory for all material (i.e. $\mid z$-score $\mid$ were $\geq 3$ ). While Lab 7 did not report specific issues, which could explain the obtained results, Lab 18 reported that skin pieces were found in the provided carcass and drumstick material. However, no clarifications on the high z-score for chicken fillets were given by Lab 18. In contrast to the moisture content results, all participating laboratories exhibited z-scores with satisfactory results when measuring protein content (Table 2). The observed standard deviation was in the same order of magnitude as reported in previous collaborative trials or inter-laboratory studies concerning poultry, meat and meat products (Thompson et al., 2004; Moser \& Herman, 2011) In Figure 2 the deviation of the single measurements (of each laboratory) from to the consensus values is illustrated for moisture and protein 
contents. Measurements of each type of sample (i.e. fillets, drumsticks and carcasses) in proficiency test and homogenisation study are reported. Comparison of the results of the two different studies will be done in the homogenisation study section. The overall results of the proficiency test indicated that the analytical practises of the different participants (with the exception of Lab 18) were sufficiently adequate to guarantee a reliable monitoring of moisture and protein contents in the provided homogenised samples within the different NRLs. As the moisture content results of Lab 18 were unsatisfactory for all types of materials, the results provided for the homogenisation study were omitted.

The possible presence of small skin and bones pieces in drumstick and carcasses homogenised material, as reported by Lab 18, is a well-known problem frequently associated with this type of samples. At the moment, no optimised homogenisation procedure has been developed as this issue seems to be inherent to the nature and the constituents of the material itself. This anatomical diversity has a large impact on the sample preparation step and consequently influences the outcome of the moisture and protein content measurements. This step, although so far underestimated within European legislation, appeared to be the crucial point in the whole procedure. It is stressed that Lab 18 reported unsatisfactory results for all types of sample material provided, i.e. also breast fillets which contains no bone material. Therefore, the reported small skin and bone pieces by Lab 18 were not believed to be a direct cause of the unsatisfactory results from this lab in this proficiency test. In an attempt to evaluate the effect of the different sample homogenisation methods available among the European NRLs, we have conducted the second part of this study, the sample homogenisation study.

\subsection{Sample homogenisation study}

The z-scores of moisture and protein content measurements for fillets, drumsticks and carcasses are shown in Table 2 as well. The two-dimensional representation of the homogenisation study is illustrated in Figure 1D, 1F, 1E with Youden plots. Lab 19 reported results that were judged as 
unsatisfactory for moisture and protein content in fillet samples (i.e. z-scores -5.13 and 3.31, respectively). Another participant, which reported an unsatisfactory result was Lab 5, with a z-score of 3.34 for the moisture content in drumsticks. Moreover, Lab 19 reported questionable results for moisture and protein content in drumsticks (i.e. z-scores -2.10 and 2.51, respectively). Two more labs reported questionable results. Lab 10 for protein content in carcasses (z-score 2.11) and Lab 16 for protein content in drumsticks (z-score -2.15). Neither of the four mentioned laboratories reported to have encountered any problems and did not provide any particular remarks that could explained the obtained results. As for the proficiency test, Figure 2 illustrated the deviation of each duplicate measurement (of each laboratory) to the assigned values for moisture and proteins contents, respectively. Measurements of each type of sample (i.e. fillets, drumsticks and carcasses) in proficiency test and homogenisation study are compared. As observed, a broad range in the deviation from the consensus value was seen for each individual sample tested within the homogenisation study for both moisture and proteins measurements. The between-laboratory standard deviations observed in the sample homogenisation study were 1.5 (fillets and carcasses) to almost 4 times (drumsticks) higher than in the proficiency test on pre-homogenised samples (Table 2). This shows that the different practices of homogenisation in each of the laboratories contributes significantly to the variance in results.

In order to relate the results of the sample homogenisation study with the different in-house sample preparation procedures, we have requested the NRLs to record some parameters such as environmental conditions, temperature of the samples at the end of the homogenisation step, homogenisation equipment and time required for the sample preparation. Although sample particle size distribution would also be of interest, not all participants were equipped to perform these measurements. Temperature after homogenisation and time required for this step are reported in Table 3 and Table 4, respectively. Large variations in the sample temperature after homogenisation (i.e. ranging from $-20{ }^{\circ} \mathrm{C}$ to $25^{\circ} \mathrm{C}$ ) and the time required for sample preparation (i.e. between 5 and 45 minutes for chicken fillets) were reported. Similarly, the relative humidity in the laboratories 
varied from a minimum of $26 \%$ to a maximum $80 \%$ (self-reporting of NRLs). Furthermore, participants reported the type of equipment used for homogenisation (e.g. mincers for samples at ambient temperature, cutters for frozen samples) and other parameters, such as the sample conditioning with liquid nitrogen or ambient thawing. As neither ISO 937 nor ISO 1442 prescribe the use of specific processing equipment nor provide constrains about environmental conditions, (e.g. sample temperature during or after homogenisation), these factors, separately or in combinations, may be responsible for the elevated between-laboratory and within-laboratory observed variation in the homogenisation study.

In this study, the processing parameters reported by the NRLs were not investigated separately as NRLs were instructed to apply their in-house practises for sample homogenisation. Therefore, correlating single parameters to deviating moisture or protein results was not possible as parameters varied simultaneously within one NRL. Nevertheless, the present study provided a strong indication that sample homogenisation influences the bias and variance of results. With the aim of a future harmonisation of 'best practices', separate studies assessing all aspects of sample homogenisation should be performed under controlled conditions in order to exactly determine the influence on experimental determined moisture and protein content of poultry meat. Furthermore, we also recommend to closely monitor environmental conditions during storage and sample preparation (e.g. temperature, air humidity), control the degree of homogenisation (e.g. particle size distribution analysis, micrographs, etc.), apply appropriate storage conditions to unprocessed and processed samples (e.g. gas tight, no leakage, no ice formation) as all these might contribute to increase variability and bias during measurements.

\section{Conclusions}

The proficiency test revealed generally satisfactory results, as only one out of 18 NRLs produced unsatisfactory results and one laboratory produced questionable results ( $\mid z$-scores $\mid$ between 2 and 3) for moisture content measurements. For protein content measurements, all z-scores were 
satisfactory. Therefore, the outcome of the proficiency test supports the conclusion that almost all participants were able to produce reliable results for moisture and protein contents in three different poultry samples.

In line with the general outcome of the proficiency test, the sample homogenisation study revealed satisfactory results as well. Only four laboratories produced unsatisfactory or questionable results. Temperature of the samples, duration of the homogenisation process, relative humidity of the laboratory, equipment used for homogenisation and sample conditioning (e.g. liquid nitrogen, ambient thawing) varied among participants. However, since all participants reported different combinations of the above-mentioned variables, it is not possible to undoubtedly relate each and every one of these variables to their respective z-scores. Nevertheless, it is evident that the degree of freedom in the homogenisation procedure as defined in European Commission Regulation (EC) $543 / 2008$ has an effect on the moisture and protein content in poultry meat. This may result in significant differences between NRLs. Therefore, harmonisation of the different procedure and/or definition of a new optimal procedure is required to improve the results among the NRLs within the European Union.

\section{Acknowledgements}

The organisers of the study thank the experts from the European National Reference Laboratories for monitoring moisture in poultry meat for their participation and support. Furthermore, the work done by RIKILT Wageningen University \& Research and Joint Research Centre - Geel colleagues who are not in the author list and who assisted with the laboratory work, logistics and statistical evaluation is acknowledged. This work was partly financed by the Dutch Ministry of Economic affairs, BAS number WOT-02-005-002.

\section{References}

Commission of the European Communities, Directorate General for Agriculture (1993). 
Physiological water content of frozen and quick frozen chicken and turkey parts - Control methods for extraneous water, Office for Official Publications of the European Communities, ISBN 92-826-6913-0.

https://publications.europa.eu/en/publication-detail/-/publication/005eba23-0113-4155-a03e124d5b555802/language-en/format-PDF/source-86218240, last visited: 8 February 2019.

Commission Regulation (EC) No 543/2008 of 16 June 2008 laying down detailed rules for the application of Council Regulation (EC) No 1234/2007 as regards the marketing standards for poultry meat (Official Journal, L 157, 17 June 2008), last amended by Commission Regulation (EU) No 519/2013 of 21 February 2013 (Official Journal, L 158, 10 June 2013).

Council Regulation (EC) No 1234/2007 of 22 October 2007 establishing a common organisation of agricultural markets and on specific provisions for certain agricultural products (Single CMO Regulation) (Official Journal, L 299, 16 November 2007); last amended by Council Regulation (EU) No 517/2013 of 13 May 2013 (Official Journal, L 158, 10 June 2013).

Elahi, S., \& Hopkins, D. (2016). Study on the state of play of processing technologies and the absorption of water in poultry meat. European Commission, Directorate-General for Agriculture and Rural Development, ISBN 978-92-79-54862-8. $\underline{\text { https://ec.europa.eu/agriculture/sites/agriculture/files/external-studies/2016-water-in- }}$ poultrymeat/final-report en.pdf Accessed 8 February 2019.

Elahi, S., \& Topping, J. (2012). Study of the physiological water content of poultry reared in the EU, LGC, Teddington, United Kingdom http://ec.europa.eu/agriculture/sites/agriculture/files/external-studies/2012/water-inpoultry/fulltext_en.pdf Accessed 8 February 2019.

Isengard, H-D. (1995). Rapid water determination in foodstuffs. Trends in Food Science \& Technology, 6, 155-162. https://doi.org/10.1016/S0924-2244(00)89024-X.

ISO (International Organization for Standardization) (1978). ISO 937:1978, Meat and meat products - Determination of nitrogen content (Reference method), Geneva, Switzerland: International 
Organization for Standardization.

ISO (International Organization for Standardization) (1997). ISO 1442:1997 ( $2^{\text {nd }}$ edition), Meat and meat products - Determination of moisture content (Reference method), Geneva, Switzerland: International Organization for Standardization.

ISO (International Organization for Standardization) (2015). ISO 13528:2015 (2 ${ }^{\text {nd }}$ edition), Statistical methods for use in proficiency testing by interlaboratory comparison, Geneva, Switzerland: International Organization for Standardization.

ISO (International Organization for Standardization) (2006). ISO Guide 35:2006 (3 ${ }^{\text {rd }}$ edition), Reference materials — General and statistical principles for certification, Geneva, Switzerland: International Organization for Standardization.

Moser, C., \& Herman, K. (2011). Method for the Rapid Determination of Protein in Meats Using the CEM Sprint ${ }^{\mathrm{TM}}$ Protein Analyzer: Collaborative Study. Journal of AOAC International, 94(5), 1555-1561.http://dx.doi.org/10.5740/jaoacint.CS2011 04.

Sáez-Plaza, P., Navas, M-J., Wybraniec, S., Michałowsi, T., \& García Asuero, A. (2013). An Overview of the Kjeldahl Method of Nitrogen Determination. Part II. Sample Preparation, Working Scale, Instrumental Finish, and Quality Control. Critical Reviews in Analytical Chemistry, 43(3), 224-272. https://doi.org/10.1080/10408347.2012.751787.

Thompson, M., Ellison, S.L.R., \& Wood, R. (2006). The international harmonized protocol for the proficiency testing of analytical chemistry laboratories. Pure Applied Chemistry, 78(1), 145-196. https://dx.doi.org/10.1351/pac200678010145.

Thompson, M., Owen, L., Wilkinson, K., Wood, R., \& Damant, A. (2002). A comparison of the Kjeldahl and Dumas methods for the determination of protein in foods, using data from a proficiency testing scheme. The Analyst, 127, 1666-1668. http://dx.doi.org/10.1039/b208973b.

Thompson, M., Owen, L., Wilkinson, K., Wood, R., \& Damant, A. (2004). Testing for bias between the Kjeldahl and Dumas methods for the determination of nitrogen in meat mixtures, by using data from a designed interlaboratory experiment. Meat Science, 68, 631-634. 
http://dx.doi.org/10.1016/j.meatsci.2004.05.016. 


\section{Figure captions}

Figure 1: Youden plots of z-scores for moisture contents (x-axes) versus z-scores for protein contents (y-axes) for each laboratory participating in the proficiency test $(1 \mathrm{~A}, 1 \mathrm{~B}, 1 \mathrm{C})$ and in the homogenisation study (1D, 1E, 1F). Results for fillets (1A, 1D), for drumsticks (1B, 1E) and carcasses (1C 1F). Laboratories inside the green rectangle (blue diamonds) had "satisfactory results". Laboratories marked with orange diamonds had "questionable results" and laboratories marked with red diamonds had "unsatisfactory results".

Figure 2: Deviation from the assigned values (in Table 3) for each duplicate measurement of moisture contents (top) and protein contents (bottom) performed by each NRL for the proficiency test (left section for each lab) and the homogenisation study (right section for each lab). Symbol shapes represent product types as described in the figure legend.

\section{Table captions}

Table 1: Homogeneity evaluation of reference samples (according to ISO 13538).

Table 2: Overview of the results of both proficiency test and homogenisation study for fillets, drumsticks and carcasses. Mean results, $z$-scores, consensus values, target and observed standard deviation (s.d.) and coefficient of variance (CV\%) of moisture- and proteins content are shown. Blanks indicate that participants have not requested these sample material. Results of the proficiency test and the sample homogenisation study were analysed according to ISO 13258.

Table 3: Sample temperatures after homogenisation as reported by participants.

Table 4: Time required to prepare one homogenised sample as reported by participants. 

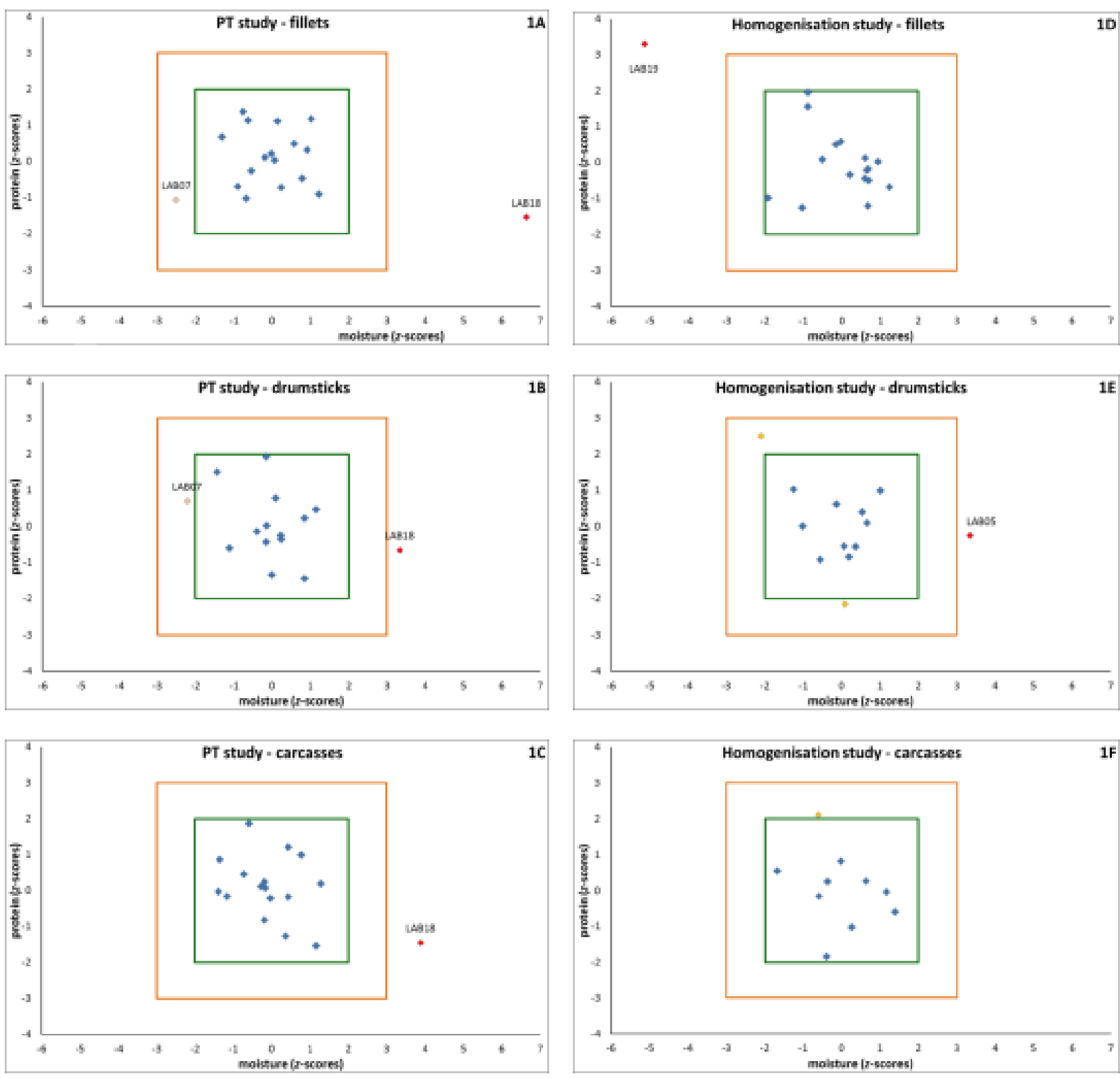
Figure 2
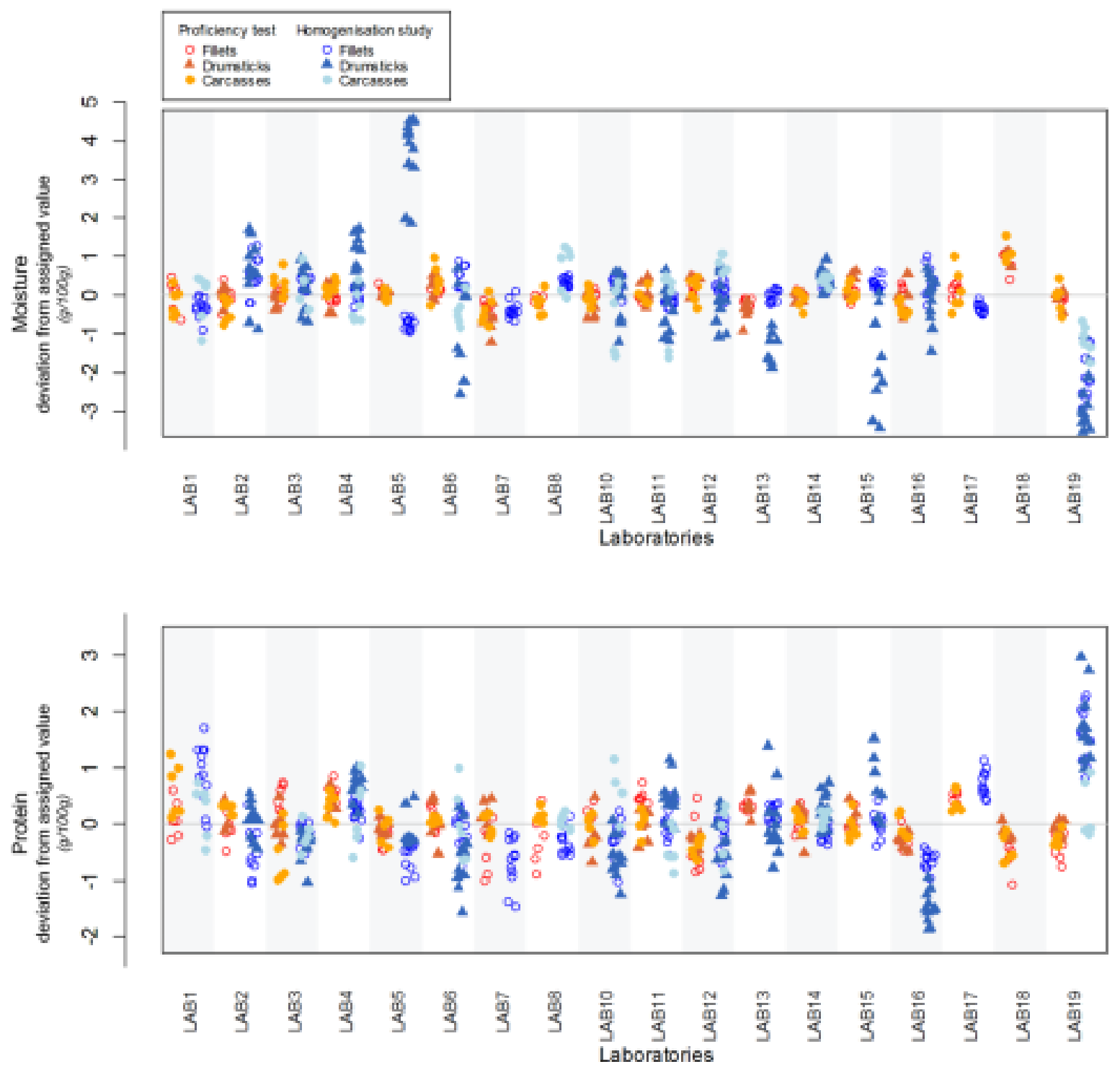


\section{Table 1}

\begin{tabular}{r|cc|cc|cc} 
& \multicolumn{2}{|c|}{ Breast fillets } & \multicolumn{2}{c|}{ Drumsticks } & \multicolumn{2}{c}{ Carcasses } \\
& Moisture & Protein & Moisture & Protein & Moisture & Protein \\
\hline mean & 74.10 & 24.34 & 67.62 & 19.28 & 62.75 & 18.13 \\
$\sigma_{\text {Target }}[\%]$ & $\mathbf{1 . 0}$ & $\mathbf{1 . 0}$ & $\mathbf{1 . 5}$ & $\mathbf{1 . 5}$ & $\mathbf{2 . 0}$ & $\mathbf{2 . 0}$ \\
$\sigma_{\text {Target }}$ & 0.74 & 0.24 & 1.01 & 0.29 & 1.25 & 0.36 \\
$0.3^{*} \sigma_{\text {Target }}$ & 0.22 & 0.07 & 0.30 & 0.09 & 0.38 & 0.11 \\
$s_{\mathrm{x}}$ & 0.06 & 0.09 & 0.31 & 0.12 & 0.29 & 0.21 \\
$s_{\mathrm{w}}$ & 0.11 & 0.10 & 0.12 & 0.17 & 0.17 & 0.17 \\
$s_{\mathrm{s}}$ & n.c. & 0.06 & 0.30 & 0.04 & 0.27 & 0.17 \\
$s_{\mathrm{s}} \leq 0.3 * \sigma_{\text {Target }}$ & passed & passed & passed & passed & passed & not passed \\
\hline
\end{tabular}

$\sigma_{\text {Target }}=$ standard deviation for PT assessment (estimated based previous studies by Elahi \& Hopkins, 2016); $s_{\mathrm{x}}=$ standard deviation of the sample averages; $s_{\mathrm{w}}=$ within-sample standard deviation; $s_{\mathrm{s}}=$ between-sample standard deviation; n.c. $=$ not computable (from ANOVA: $\mathrm{MS}_{\text {between }}<\mathrm{MS}_{\text {within }}$ ). 
Table 2

PROFICIENCY TEST

HOMOGENISATION STUDY

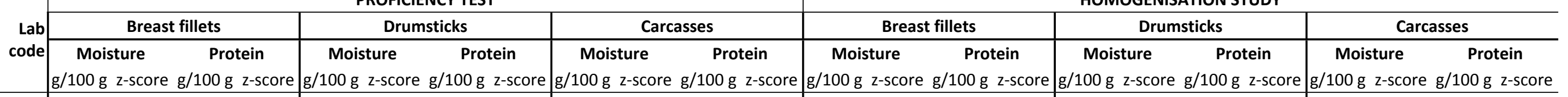

$\begin{array}{lllll}74.10 & -0.02 & 24.43 & 0.22\end{array}$

\begin{tabular}{lllll|llll|llllllll} 
LAB2 & 74.03 & -0.54 & 24.22 & -0.27 & 67.47 & 0.09 & 19.31 & 0.78 & 62.28 & -1.35 & 18.42 & 0.86 & 74.76 & 1.25 & 23.79 & -0.68 \\
\hline
\end{tabular}

\begin{tabular}{llllll|lllllllllllll} 
LAB3 & 74.12 & 0.14 & 24.81 & 1.11 & 67.32 & -0.40 & 19.10 & -0.14 & 63.02 & 1.17 & 17.63 & -1.54 & 74.50 & 0.65 & 24.02 & -0.21
\end{tabular}

\begin{tabular}{l|llll|llllll|lllll|llll} 
LAB4 & 74.01 & -0.75 & 24.92 & 1.38 & 67.40 & -0.15 & 19.57 & 1.94 & 62.90 & 0.77 & 18.46 & 0.98 & 74.23 & -0.01 & 24.41 & 0.58 & 69
\end{tabular}

\begin{tabular}{l|llll|llll} 
LAB5 & 74.21 & 0.79 & 24.13 & -0.47 & 67.51 & 0.24 & 19.05 & -0.36
\end{tabular}

\begin{tabular}{l|llll|llll} 
LAB6 & 74.22 & 0.91 & 24.47 & 0.31 & 67.69 & 0.84 & 19.18 & 0.23
\end{tabular}

$\begin{array}{lllllllll}\text { LAB7 } & 73.78 & -2.51 & 23.88 & -1.06 & 66.77 & -2.22 & 19.29 & 0.71\end{array}$

\begin{tabular}{l|llll} 
LAB8 & 73.99 & -0.90 & 24.04 & -0.70
\end{tabular}

LAB09

$\begin{array}{lllll}\text { LAB10 } & 74.18 & 0.58 & 24.55 & 0.49\end{array}$

$\begin{array}{llll}67.10 & -1.11 & 19.00 & -0.59 \\ 67.51 & 0.22 & 19.08 & -0.25\end{array}$

\begin{tabular}{l|cccc|ccccc} 
& & &
\end{tabular}

\begin{tabular}{l|llll|llll|} 
LAB14 & 74.08 & -0.18 & 24.38 & 0.11 & 67.40 & -0.14 & 19.14 & 0.02
\end{tabular}

\begin{tabular}{l|llll|llll} 
LAB15 & 74.11 & 0.07 & 24.35 & 0.04 & 67.79 & 1.15 & 19.24 & 0.47
\end{tabular}

\begin{tabular}{l|llll|llll} 
LAB16 & 74.13 & 0.24 & 24.03 & -0.72 & 67.44 & 0.00 & 18.83 & -1.34
\end{tabular}

$\begin{array}{lllll}\text { LAB17 } & 74.24 & 1.02 & 24.83 & 1.17\end{array}$

\begin{tabular}{lllll|llll} 
LAB18 & 74.97 & 6.64 & 23.68 & -1.54 & 68.45 & 3.33 & 18.98 & -0.65
\end{tabular}

\begin{tabular}{l|llll|} 
LAB19 & 74.02 & -0.67 & 23.90 & -1.02 \\
\hline
\end{tabular}

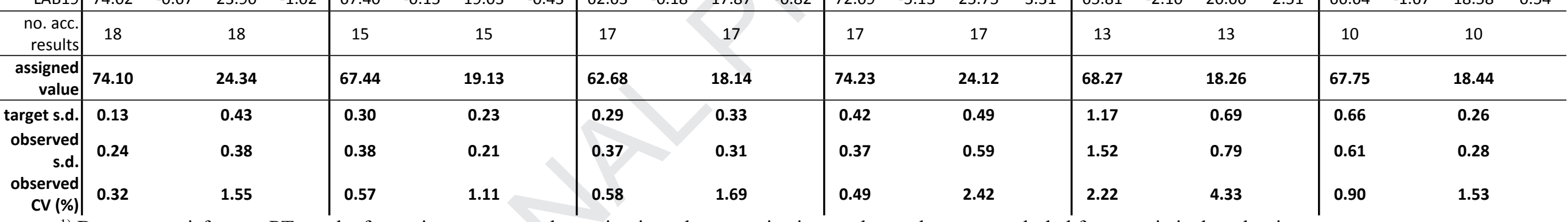

1) Due to unsatisfactory PT results for moisture content determinations, homogenisation study results were excluded from statistical evaluation. 
Table 3

\begin{tabular}{l|l} 
Laboratory & End temperature of sample $\left({ }^{\circ} \mathrm{C}\right)$ \\
\hline $15,16,17,19$ & -20 to -15 \\
$1,2,3,8,11,13,14,18$ & 0 to 5 \\
$4,6,7,10$ & 10 to 15 \\
$5,12,15$ & 15 to 25 \\
\hline
\end{tabular}

Table 4

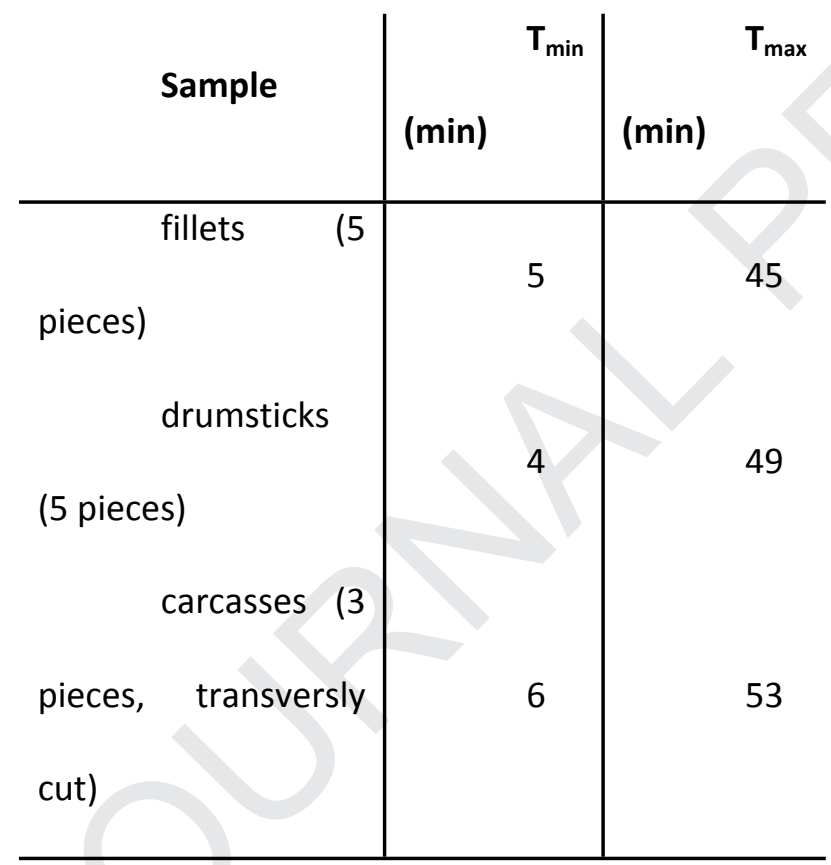




\section{Highlights}

- Proficiency test showed satisfactory results for moisture and protein contents.

- Homogenisation introduced analytical bias for moisture and protein contents.

- Different poultry cuts resulted in different scatter patterns for analytical results.

- Drumstick samples showed highest variability of the results. 


\section{Declaration of interests}

$\bigotimes$ The authors declare that they have no known competing financial interests or personal relationships that could have appeared to influence the work reported in this paper.

$\square$ The authors declare the following financial interests/personal relationships which may be considered as potential competing interests: 